\title{
TMS Announces New Meeting on Engineering Safety; Congratulations to Two TMS Members \\ themagazine
}

\section{Introducing: Safety Congress 2020}

TMS is excited to announce plans for a new event of its kind - the Congress

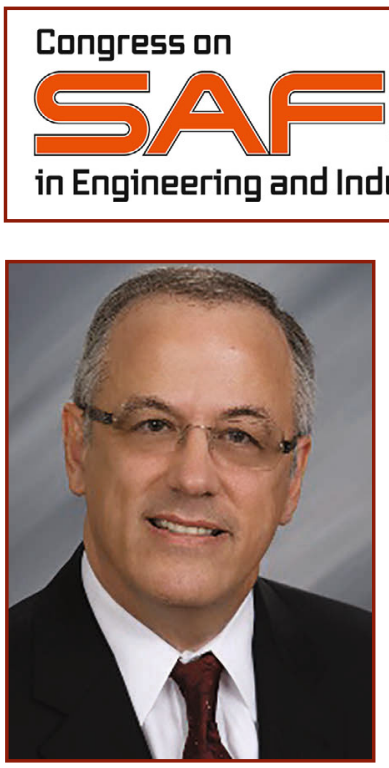

Roland Moreau the congress, scheduled for June 21-24, 2020, in Philadelphia, Pennsylvania, is sponsored by the American Institute of Mining, Metallurgical, and Petroleum Engineers (AIME), the Association for Iron \& Steel Technology (AIST), the Society for Mining, Metallurgy \& Exploration (SME), the Society of Petroleum Engineers (SPE), and TMS. Co-sponsoring societies include the (AIChE), the American Society of Civil Engineers (ASCE), ASME, and

\section{on Safety in Engineering and Industry (Safety Congress 2020). \\ The inaugural installment of} American Institute of Chemical Engineers the National Academies of Sciences, Engineering, and Medicine (NAS).

Rather than focusing on one industry or the general topic of safety, Safety Congress 2020 has been designed to cross a wide spectrum of industries and settings - as evidenced by the array of sponsoring and co-sponsoring organizations involved - to give participants the opportunity to learn from others who are addressing similar safety problems, but through different approaches, processes, and best practices. The meeting presents a unique opportunity for attendees to convene with leadership across industries and the breadth of science and engineering disciplines to address shared safety management challenges (including operational, process, and project safety; safety leadership and culture; safety management system design and implementation; and effective use of data metrics to support risk-based decision making).

"I think that one of the greatest potential contributions for Safety Congress 2020 is to allow different industries to learn from each other, foster new networks, and address more effective ways to integrate safety considerations at the university level," said Roland Moreau, congress program chair, 2018 AIME President, and ExxonMobil (retired). "In keeping with its multi-industry approach, Safety Congress 2020 is envisioned to support a broad cross-section of management and safety professionals in expanding their skillsets for the advancement of their organizations - and themselves."

At press time, the following breakout sessions are planned for Safety Congress 2020:

- Management and Systems: covering the role of health, safety, and environment management systems; the integration of safety in regulatory frameworks; addressing funding issues; and more.

- Technology and Techniques: looking at the role of unmanned aircraft systems in enhancing safety; incident investigations; the role of technology and innovation in improving safety performance; and more.

- Human Resources: taking on the topics of leadership development; preparing university students for industry; and more.

Additionally, keynote and plenary topics for the congress include:

- The importance of safety and value of networking across sectors

- The value proposition for safety

- Executing an effective risk management program

- Leading the future of safety by learning from the past

Further program details are still under development, as well as information on registration, professional development opportunities, and networking events. For more information and to sign up for e-mail updates visit www.SafetyCongress.org. 


\section{Carter and Mathaudhu Honored as Early Career Scientists}

Congratulations to two TMS members who were named recipients of the Presidential Early Career Awards for Scientists and Engineers (PECASE), the highest honor bestowed by the U.S. government on science and engineering professionals in the early stages of their independent research careers. Jennifer L.W. Carter, an assistant professor in the Department of Materials Science and Engineering at Case Western Reserve University, and Suveen N. Mathaudhu, associate professor and Materials Science and Engineering Chair at the University of California, Riverside, were both recognized for their achievements in July 2019.

A TMS member since 2007, Carter is the recipient of the 2012 American Institute of Mining, Metallurgical, and Petroleum Engineers (AIME) Henry deWitt Smith Scholarship, the 2014 Structural Materials Division (SMD) Young Leaders Professional Development Award, and the 2019 TMS/Federation of European Materials Societies (FEMS)
Young Leaders International Scholar Award. She has been actively involved in several TMS technical and functional committees and is a past chair and current member of the Diversity Committee.

Mathaudhu has participated on many TMS technical committees since he became a member in 2000, serving the Society across the Light Metals, Materials Processing \& Manufacturing, and Structural Materials Divisions. In 2015, Mathaudhu received the American Association of Engineering Societies' (AAES) Norm Augustine Award for Outstanding Achievement in Engineering Communications.

The PECASE are coordinated by the U.S. Office of Science and Technology Policy with the participating agencies and departments to recognize individuals who contribute to the advancement of science, technology, education, and math (STEM) education and who demonstrate commitment to community service through scientific leadership, public education, or community outreach.

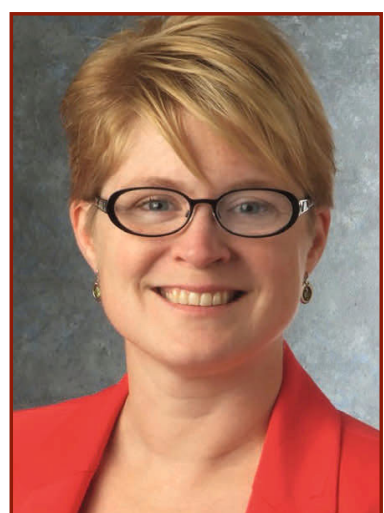

Jennifer L.W. Carter

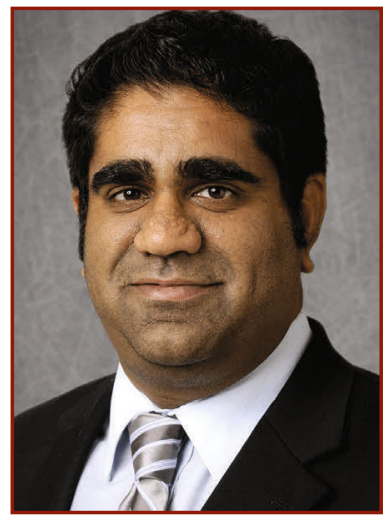

Suveen N. Mathaudhu

\section{TMS Board Convenes in Pittsburgh}

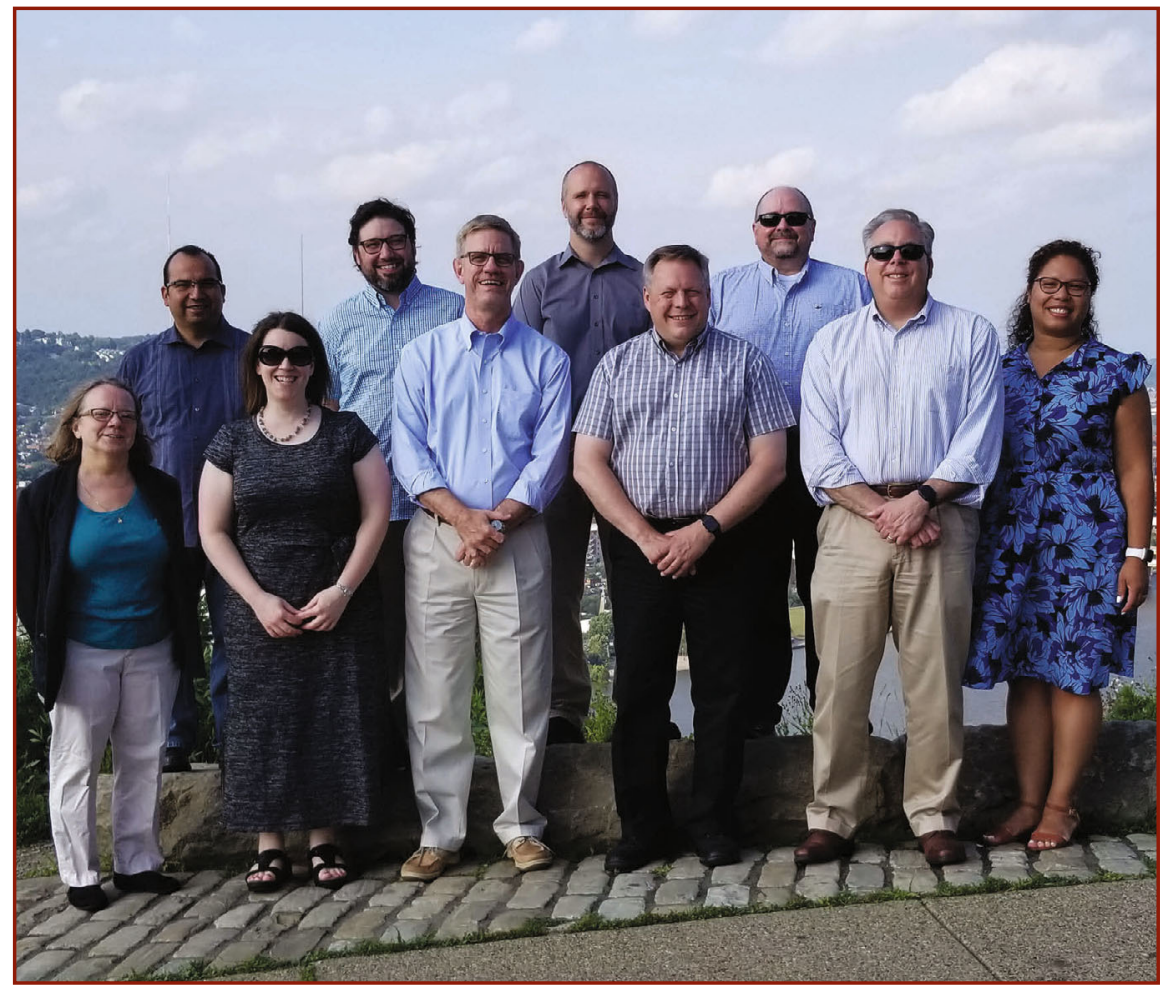

The TMS Board of Directors gathered at TMS headquarters in Pittsburgh, Pennsylvania, on July 19-21, 2019, for its annual summer board retreat. Front row, left to right: Cindy Belt, Extraction \& Processing Division Chair; Alexis Lewis, Membership \& Student Development Director; Kevin Hemker, Past President; Jim Foley, TMS President; Mark Stoudt, Materials Processing \& Manufacturing Division Chair; and Michele Manuel, Content Development \& Dissemination Director. Back row, left to right: Raymundo Arroyave, Functional Materials Division Chair; John Howarter, Public \& Governmental Affairs Director; Brad Boyce, Programming Director; and Jim Robinson, TMS Secretary/ Executive Director. Not pictured are: Thomas Battle, TMS Vice President; Adrian Deneys, Financial Planning Officer; Chester Van Tyne, Professional Development Director; Daniel Miracle, Structural Materials Division Chair; and Eric Nyberg, Light Metals Division Chair. 


\section{TMS Welcomes New Members}

\section{The TMS Board of Directors approved professional membership for the following individuals at its July 2019 meeting. Please join us in congratulating and welcoming them to all the privileges and benefits of TMS membership.}

\section{Al Washahi, Mohammed; Sohar Aluminium Company, Oman}

Alansari, Atif; Emirates Global Aluminium, United Arab Emirates

Aromaa, Jari J.; Aalto University, Finland

Bjorgvinsson, Sigurjon K.; Alcoa, Iceland

Budding, Wesley J.R.; Quantillion Technologies, Netherlands

Cani, Alessio; SiderAlloys, Italy

Chandola, Nitin; University of Florida, United States

Chen, Pengyu; United States

Chetty, Jeremy; South Africa

Chokshi, Atul; Indian Institute of Science, India

Crouzet, Sylvain; REEL Alesa, France

Deik, David G.; United States

Demesa, Abayneh; Abo Akademi University, Finland

Dimou, Sotirios; Mytilineos SA, Greece

Dionne, Jean-François; Switzerland

Dyroy, Are; Norway

El Khoja, Mahmud; Pyrotek Inc., United States

Etedgi, Cgarli; Kmg, Israel

Fernandez, Joaquin Fernandez; Alcoa, Spain

Fernandez Gomez, Hector; Manpowergroup Solutions SLU, Spain

Gandia, Thomas; REEL Alesa, France

Ganguly, Partha; United States

Gilbert, Andre; Stas Inc., Canada

Girault, Guillaume; REEL Alesa, France

Glen, Crystal C.; United States

Gorshunova, Margarita; Hydro Aluminium Rolled Products $\mathrm{GmbH}$, Germany
Hummel, Kyle R.; Contour Hardening Inc., United States

Iwa, Mayowa; Danvic Petroleum International, Nigeria

Karlsen, Morten; Hydro Aluminium, Norway

Katz, Gary; Katz Water Technologies, United States

Kiligaridis, Danis; Alumil SA, Greece

Kirchhofer, Rita; Exponent Inc., United States

Kolioumpas, Nikolaos; ANOXAL SA, Greece

Kontaratos, Antonis; ANOXAL SA, Greece

Lee, Dongrim; Google LLC, United States

Luan, Jian; Dalian Bihai Enviornmental Protection Equipment Co. Ltd., China

Makama, Zakari; United States

Malhotra, Sumit; AES Drilling Fluids, United States

Mhaskar, Nauman; Weatherford, United States

Muehlen, Petra; Advancetex International Pty, Germany

Munger, Steve; STAS Inc., Canada

Noack, Clinton; United States

Norton, M. Grant; Washington State University, United States

Olsen, Havard M.; GE Power Norway, Norway

Ose, Sivert; GE Power Norway AS, Norway

Panchal, Nitesh N.; NMT Engineering \& Services, India

Raja, Pavan; Rice University, United States

Risse, Marcel S.; BSH Home Appliances Corp., Germany

Romero, Rocio Belen; Alvar Aluminio Argentino S.A.I.C, Argentina

Schneider, Josephine; Hydro Aluminium Rolled Products $\mathrm{GmbH}$, Germany

Shaber, Nicholas L.; Wagstaff Inc., United States
Shah, Jiten; PDA LLC, United States

Shipley, Roch J.; Professional Analysis and Consulting Inc., United States

Singh, Amarendra Kumar; Indian Institute of Technology Kanpur, India

Sis, Adem; Trimet Aluminum SE Plant Essen, Germany

Soederholm Hansen, Magnus; Neatec, Norway

Soto, Karla; United States

Spiess, Peter; Hydro Aluminium Rolled Products $\mathrm{GmbH}$, Germany

Stathopoulos, Pantelis K.; Elvalhalcor $S A$, Greece

Steingrimsson, Arnfinnur Aegir; Alcoa, Iceland

Thibault, Yves; Canmet MINING, Natural Resources Canada, Canada

Tower, Eric J.; Pyrotek, United States

Triantafyllou, Anastasios; Mytilinaios SA, Greece

Tzevelekou, Theofani; ELKEME SA, Greece

Valciu, Serena; Hydro, Norway

Vass, Jeanette; United States

Vrancken, Bey; Lawrence Livermore National Laboratory, United States

Wang, Zhang; Alcoa, Norway

Worner, Steven M.; Corval Group, United States

Woss, Alexander; Hammerer Aluminium Industries, Austria

Wu, Yongyu; Dalian Bihai Environmental Protection Equipment Co. Ltd., China

Yousseff, Joumani; Fives Solios, France

Zakaria, Muzdalifah; Petronas Research, Malaysia

Zheng, Ruirui; Dalian Bihai Environmental Protection Equipment Co. Ltd., China 